This item was submitted to Loughborough's Research Repository by the author.

Items in Figshare are protected by copyright, with all rights reserved, unless otherwise indicated.

\title{
Identification of single-site gold catalysis in acetylene hydrochlorination
}

\section{PLEASE CITE THE PUBLISHED VERSION}

https://doi.org/10.1126/science.aal3439

\section{PUBLISHER}

American Association for the Advancement of Science $(\subset)$ The Authors

\section{VERSION}

AM (Accepted Manuscript)

\section{PUBLISHER STATEMENT}

This work is made available according to the conditions of the Creative Commons Attribution-NonCommercialNoDerivatives 4.0 International (CC BY-NC-ND 4.0) licence. Full details of this licence are available at: https://creativecommons.org/licenses/by-nc-nd/4.0/

\section{LICENCE}

CC BY-NC-ND 4.0

\section{REPOSITORY RECORD}

Malta, Grazia, Simon Kondrat, Simon J. Freakley, Catherine J. Davies, Li Lu, Simon R. Dawson, Adam Thetford, et al.. 2017. "Identification of Single-site Gold Catalysis in Acetylene Hydrochlorination". Loughborough University. https://hdl.handle.net/2134/33205. 


\section{Identification of single site gold catalysis in acetylene hydrochlorination}

Grazia Malta $^{\mathrm{a}}$, Simon A. Kondrat ${ }^{\mathrm{a}}$, Simon J. Freakley ${ }^{\mathrm{a}}$, Catherine J. Davies ${ }^{\mathrm{a}}$, Li Lu ${ }^{\mathrm{b}}$, Simon Dawson $^{\mathrm{a}}$, Adam Thetford ${ }^{\mathrm{c}, \mathrm{d}}$ Emma K. Gibson $^{\mathrm{c}, \mathrm{d}}$, David J. Morgan ${ }^{\mathrm{a}}$, Wilm Jones ${ }^{\mathrm{c}}$, Peter P.

Wells $^{\text {c,dee }}$, Peter Johnston ${ }^{\mathrm{f}}$, C. Richard A. Catlow ${ }^{\mathrm{a}, \mathrm{c}, \mathrm{d}}$ Christopher J. Kiely ${ }^{\mathrm{b}}$ and Graham J. Hutchings ${ }^{a^{*}}$

${ }^{a}$ Cardiff Catalysis Institute, School of Chemistry, Cardiff University, Main Building, Park Place, Cardiff, CF10 3AT, UK.

${ }^{\mathrm{b}}$ Department of Materials Science and Engineering, Lehigh University, 5 East Packer Avenue, Bethlehem, Pennsylvania, PA 18015, USA.

${ }^{\mathrm{c}}$ UK Catalysis Hub, Research Complex at Harwell, RAL, Oxford, OX11 0FA, UK.

${ }^{\mathrm{d}}$ Kathleen Lonsdale Building, Department of Chemistry, University College London, Gordon Street, London, WC1H 0AJ, UK.

e School of Chemistry, University of Southampton, Southampton, SO17 1BJ, UK.

${ }^{\mathrm{f}}$ Process Technologies, Johnson Matthey PLC, Billingham TS23 1LB, UK.

*hutch@cf.ac.uk 


\begin{abstract}
There remains considerable debate over the active form of gold under operating conditions of a recently validated gold catalyst for acetylene hydrochlorination, . We have performed an in situ x-ray absorption fine structure study of $\mathrm{Au} / \mathrm{C}$ catalysts under acetylene hydrochlorination conditions and show that highly active catalysts comprise single-site cationic Au entities whose activity correlates with the ratio of $\mathrm{Au}(\mathrm{I})$ : $\mathrm{Au}(\mathrm{III})$ present. We demonstrate that these $\mathrm{Au} / \mathrm{C}$ catalysts are supported analogs of single-site homogenous Au catalysts and propose a mechanism, supported by computational modelling, based on a redox couple of $\mathrm{Au}(\mathrm{I}): \mathrm{Au}(\mathrm{III})$ species.
\end{abstract}

A major environmental landmark occurred in late 2015 with the commercialization of carbonsupported gold as a catalyst for acetylene hydrochlorination in China (1, 2). Since the 1950s, mercuric chloride supported on carbon has been used as a catalyst for the production of vinyl chloride monomer (VCM) via this reaction. In 1985, Hutchings predicted (3) that gold should be the best catalyst for this reaction and subsequently showed this to be the case by experiment (4). During the past decade, the manufacture of VCM has increased markedly in China, partly because of the availability of coal as a feedstock for acetylene production. However, this trend has increased the environmental burden resulting from mercury pollution and, with the signing of the Mimimata accord (5), a replacement for mercuric chloride in the acetylene hydrochlorination reaction was mandated. The use of carbon-supported gold for this reaction represents the first time in more than 50 years that there has been a total change in the catalyst composition for the manufacture of a major commodity chemical.

The key question that remains is 'What is the nature of the active gold species under acetylene hydrochlorination reaction conditions?' Ex-situ spectroscopy and electron microscopy (6-9) studies have suggested that gold nanoparticles are present and the active sites are cationic gold associated with these nanoparticles $(6,10)$. Recently, a possible role for $\mathrm{Au}(\mathrm{I})$ as well as $\mathrm{Au}(\mathrm{III})$ has been implicated in acetylene hydrochlorination (11) and other reactions $(12,13)$. Since the original disclosure of gold as an effective catalyst for alkyne transformations (14), numerous 
examples of $\mathrm{Au}(\mathrm{I})$ complexes have been described for such reactions, which suggests that the active gold catalyst for acetylene hydrochlorination could be a supported gold cation. Single gold cations have been implicated in heterogeneous catalysts before (15-17), but these materials either deactivate rapidly or form substantial concentrations of gold clusters or nanoparticles after reaction. We have now performed in situ x-ray absorption fine structure (XAFS) experiments to definitively show that the active catalyst for acetylene hydrochlorination predominantly comprises of $\mathrm{Au}(\mathrm{I})$ isolated cationic species analogous with the single-site homogeneous catalysis afforded by $\mathrm{Au}(\mathrm{I})$ complexes $(19,20)$. For an in situ XAFS study of these homogeneous gold catalysed reactions, see (21).

A series of $1 \mathrm{wt} \%$ Au materials supported on carbon powder were prepared by impregnation with $\mathrm{HAuCl}_{4}$ dissolved in either aqua regia, $\mathrm{HNO}_{3}$, or $\mathrm{H}_{2} \mathrm{O}$ by previously described methods (designated as $\mathrm{Au} / \mathrm{C}-\mathrm{AR}, \mathrm{Au} / \mathrm{C}-\mathrm{HNO}_{3}$ and $\mathrm{Au} / \mathrm{C}-\mathrm{H}_{2} \mathrm{O}$ respectively) (11). Scanning transmission electron microscopy (STEM) analysis of the Au/C-AR catalyst (Fig. 1A) revealed the presence of predominantly highly dispersed isolated Au species. Some dimeric Au species were also identified, although they were a relatively minor component compared to the isolated monomeric Au species (Figure S1) (22). This finding was supported by x-ray diffraction (XRD) (Fig. 1B), where no reflections associated with metallic Au nanoparticles were observed. The lack of long-range order was further corroborated by extended x-ray absorption fine structure (EXAFS) analysis (Fig. 1C), where no $\mathrm{Au}-\mathrm{Au}$ characteristic distances were detected. In addition, substantial contributions from $\mathrm{Au}-\mathrm{Cl}$ entities can be seen in the EXAFS Fourier transform (FT). Fitting a first coordination shell for $\mathrm{Au}-\mathrm{Cl}$ gave an average coordination number (CN) of 2.6 [Table S1 ] (22). Furthermore, ex-situ Cl K-edge XANES studies confirmed the presence of Au-Cl bonding (Figure S2) (22).

Further information on Au speciation can be determined from the normalized $\mathrm{Au} \mathrm{L}_{3}$ edge Xray absorption near edge structure (XANES) (see experimental SM section for full details) (22). The white-line intensity (a strong adsorption feature associated with $\mathrm{Au} 2 \mathrm{p}_{3 / 2}$ core electron excitation to unoccupied 5d or 6s states) is indicative of 5d-band occupancy; Au species with higher oxidation states (i.e. reduced 5d electron occupancy) have stronger white-line adsorption features. Analysis of the white-line intensity during XANES measurements, when compared to appropriate standards, has precedence in the literature as a reliable method of identifying $\mathrm{Au}$ oxidation state $(23,24)$. The typical normalized white-line intensity values observed for cationic $\mathrm{Au}$ standards of $\mathrm{Au}(\mathrm{III})\left(\right.$ e.g., $\left.\mathrm{KAuCl}_{4} /\left[\mathrm{AuCl}_{4}\right]^{-}\right)$and $\mathrm{Au}(\mathrm{I})\left(\right.$ e.g. $\left.\left[\mathrm{AuCl}_{2}\right]^{-}\right)$are 1.1 and 0.6 respectively and correlate well with measured values from our chosen standard materials 
(Figure S3) $(22,23,25)$. The white-line intensity (Fig. 1D) of the fresh Au/C-AR catalyst was 0.78, indicating a substantially oxidized Au speciation, with linear combination fitting showing no contribution from $\mathrm{Au}^{0}$ (within fitting error), 56\% from $\left[\mathrm{AuCl}_{2}\right]^{-}$and $44 \%$ from $\left[\mathrm{AuCl}_{4}\right]^{-}$ (Table S2) (22). Notably, we have not relied upon x-ray photoelectron spectroscopy (XPS) for characterization because of observable beam-induced photoreaction of $\mathrm{Au}^{3+}$ salts (Figure S4) (22), which will overstate $\mathrm{Au}^{0}$ content in the $\mathrm{Au} / \mathrm{C}$ catalysts. Photoreduction did not occur with synchrotron radiation in the XAFS technique because of the higher photon incident energy, which results in a significantly lower absorption cross section compared with XPS (Figure S4) (22).

The Au/C-AR catalyst has an induction period typically of 1 hour, strongly suggesting that its active form is generated under reaction conditions (11). To investigate the nature of the Au species under in situ acetylene hydrochlorination reaction conditions, we used a purpose-built micro-reactor to perform XAFS analysis while following the reaction by mass spectrometry (see experimental for details) (22). Under the dilute reaction conditions $\left(2.36 \% \mathrm{C}_{2} \mathrm{H}_{2}\right.$ and $2.40 \% \mathrm{HCl}$ ) that we needed with this apparatus, we observed increasing acetylene conversion with increasing time-on-line . However, the induction period occurred over a longer timespan (3 h) under these dilute conditions (Fig. 2A). All of the $\mathrm{Au} / \mathrm{C}$ catalysts we tested were highly selective toward VCM; no dichloroethene or chloroethane products were detected at any level of acetylene conversion.

We used in situ XAFS to monitor changes in Au speciation of the Au/C-AR catalyst upon heating to reaction temperature $\left(200^{\circ} \mathrm{C}\right)$ under an inert atmosphere prior to the addition of reactants. On heating, a decrease in white-line intensity from 0.78 at $25^{\circ} \mathrm{C}$ to 0.68 was observed, which suggests a change from a mixed $\mathrm{Au}(\mathrm{III}) / \mathrm{Au}(\mathrm{I})$ chloride speciation to a $\mathrm{Au}(\mathrm{I})$ chloride-like species. This change correlates well with the decomposition temperature of $\mathrm{AuCl}_{3}$ to $\mathrm{AuCl}$ that occurs at $\sim 160{ }^{\circ} \mathrm{C}$. (26) The white-line intensity was stable at 0.68 during the 30 min isotherm at $200{ }^{\circ} \mathrm{C}$ prior to the addition of reactant gases (Figure S5) (22). The continued absence of any detectable $\mathrm{Au}-\mathrm{Au}$ distances in the catalyst indicates that the Au remained in a highly dispersed state.

Further analysis of the $\mathrm{Au} / \mathrm{C}-\mathrm{AR}$ catalyst showed that upon introduction of the reactant gases, an immediate change in the Au $\mathrm{L}_{3}$ edge XANES spectrum occurred (Fig. 2, A and B). The white-line intensity increased from 0.68 to 0.94 during the first 20 min time-on-line, and then steadily decreased back to a stable value of 0.72 after $\sim 180 \mathrm{~min}$. This observation suggests that 
$\mathrm{Au}(\mathrm{I})$ chloride-type species initially present were oxidized to predominantly $\mathrm{Au}(\mathrm{III})$ chloride species by the reactants during the first $20 \mathrm{~min}$, and during the subsequent $160 \mathrm{~min}$ of reaction, the average oxidation state of the Au species gradually moved back toward that of $\mathrm{Au}(\mathrm{I})$ before converging to a stable condition somewhere between the two extremes. After the initial 15 min time on line, where reaction conditions reached steady-state, the measured change in relative white-line intensity correlated strongly with the simultaneously recorded VCM productivity of the catalyst (Pearson's $r$ value of -0.995 as shown in Figure S6) (22), with higher productivity being observed with lower $\mathrm{Au}$ white-line relative intensity. Importantly; no characteristic $\mathrm{Au}-\mathrm{Au}$ distances were measurable by EXAFS while the catalyst was producing VCM during the entire reaction period (Figure S7a) (22). Linear combination fitting analysis of XANES spectral data with $\left[\mathrm{AuCl}_{4}\right]^{-},\left[\mathrm{AuCl}_{2}\right]^{-}$and $\mathrm{Au}$-foil standard spectra showed a trend similar to that deduced from the white line intensity analysis (Figure S8a) (22). However, poor $\mathrm{R}$ fitting values in the linear combination fitting (Figure S9) (22) implies that our interpretation of the XANES spectral changes being solely associated with variations in the relative concentrations of $\left[\mathrm{AuCl}_{4}\right]^{-}$and $\left[\mathrm{AuCl}_{2}\right]^{-}$could be an oversimplification. XANES spectra are influenced by the hybridization of substrate molecule and metal d band orbitals $(27,28)$ and by changes in metal speciation geometry through interaction with the support (29). Both these reported complications are conceivable in this work, in the form of (i) interactions between the acetylene $\pi$ - and $\mathrm{Au}\left(5 \mathrm{~d}\right.$ ) orbitals and (ii) $\mathrm{C}-\mathrm{AuCl}_{\mathrm{x}}$ geometric effects. However, we observed a linear correlation between white-line intensity and the EXAFS derived $\mathrm{Au}-\mathrm{Cl}$ co-ordination number $(\mathrm{CN})$, at a range of reaction times (Figure S10) (22), which supports our interpretation of the white-line intensity as being directly associated with changes in the $\mathrm{Au}-\mathrm{Cl}$ speciation. Analysis of the spent catalyst by STEM-HAADF imaging confirmed the prevalence of atomically dispersed $\mathrm{Au}$ species as well as some occasional sub-nm clusters, but there was a total absence of any metallic Au nanoparticles (Fig. 2C).

To further re-enforce our findings, we performed comparable in situ XAFS studies, along with reaction effluent analysis, on corresponding $\mathrm{Au} / \mathrm{C}$ catalysts prepared with nitric acid or water. The $\mathrm{Au} / \mathrm{C}-\mathrm{HNO}_{3}$ catalysts were reported to have some activity and display comparable induction periods to the Au/C-AR catalyst (11) which was also extended by the dilute reaction conditions. Ex-situ characterization of the $\mathrm{Au} / \mathrm{C}-\mathrm{HNO}_{3}$ sample showed lower $\mathrm{Au}$ dispersion when compared to $\mathrm{Au} / \mathrm{C}-\mathrm{AR}$, with some evidence of metallic Au particles from XRD (Figure S11) (22). However, in situ EXAFS and XANES of $\mathrm{Au} / \mathrm{C}-\mathrm{HNO}_{3}$ under reaction conditions showed that the active stable catalyst was still predominantly comprised of cationic $\mathrm{AuCl}_{\mathrm{X}}$ 
species (Figures S7b and S8b) (22). The same correlation between Au $\mathrm{L}_{3}$ edge white-line intensity and catalytic activity as found for $\mathrm{Au} / \mathrm{C}-\mathrm{AR}$ materials was observed (Fig. 3A). However, the catalytic activity of the $\mathrm{Au} / \mathrm{C}-\mathrm{H}_{2} \mathrm{O}$ material, when measured under more concentrated reaction mixtures (11), was very low and showed no improvement with reaction time-on-line. This catalyst was comprised predominantly of metallic $\mathrm{Au}$ nanoparticles (as observed from XRD, Figure S11, and STEM, Figure S12) (22), and no white-line was observed in XANES (Fig. 3A) indicating very low concentrations of dispersed Au species. Indeed, this catalyst was the only one we investigated that had discernible Au-Au scattering paths in the FT of the EXAFS data and showed no characteristic $\mathrm{Au}-\mathrm{Cl}$ distances (Fig. 3B). Under reaction conditions, almost no change was observed in the in situ XANES or EXAFS spectra (Figures S7c and S8c) (22).

We also prepared a $\mathrm{Au} / \mathrm{C}$ catalyst using $\mathrm{Au}(\mathrm{I})$-thiosulfate as a precursor complex (designated $\mathrm{Au} / \mathrm{C}-\mathrm{S}_{2} \mathrm{O}_{3}$ ) that was more stable and active catalyst under reaction conditions than those made with the $\mathrm{Au}-\mathrm{Cl}$ precursor. We have demonstrated that use of a more stable cationic gold complex prepared from a range of sulphur containing ligands, such as thiosulfate, results in highly active catalysts at low gold loadings $(1,30)(1)$. The catalytic activity of $\mathrm{Au} / \mathrm{C}-\mathrm{S}_{2} \mathrm{O}_{3}$ was similar that of the steady state activity of the $\mathrm{Au} / \mathrm{C}-\mathrm{AR}$ and $\mathrm{Au} / \mathrm{C}-\mathrm{HNO}_{3}$ catalysts (Fig. 3A), but it had no induction period. As with the $\mathrm{Au} / \mathrm{C}-\mathrm{AR}$ and $\mathrm{Au} / \mathrm{C}-\mathrm{HNO}_{3}$ materials, EXAFS analysis of the fresh $\mathrm{Au} / \mathrm{C}-\mathrm{S}_{2} \mathrm{O}_{3}$ sample showed no $\mathrm{Au}-\mathrm{Au}$ distances and a substantial contribution from a Au scattering path with a low atomic number neighbour (Fig. 3B). Given the similar nature of $\mathrm{Cl}$ and $\mathrm{S}$ from an EXAFS perspective and Au-thiosulphate complexes having two Au-S bonds with an angle near $180^{\circ}$ (31) (almost identical to the molecular geometry of $\left[\mathrm{AuCl}_{2}\right]^{-}$), we cannot distinguish between $\mathrm{Au}-\mathrm{Cl}$ and $\mathrm{Au}-\mathrm{S}$ scattering paths by EXAFS. A fitting of the EXAFS data from the fresh $\mathrm{Au} / \mathrm{C}-\mathrm{S}_{2} \mathrm{O}_{3}$ catalysts (Table S1) (22) gave a $\mathrm{CN}$ of $2.0( \pm 0.1)$, showing that the Au-bonded species was the Au-thiosulfate complex. This $\mathrm{CN}$ corresponded well with the white-line intensity of 0.68 , further showing that the catalyst comprised predominantly $\mathrm{Au}(\mathrm{I})$ species before reaction (Fig. 3A). Interestingly, upon the addition of the reactant gases, a slight increase in white-line intensity to 0.78 (with concomitant $\mathrm{Au}-\mathrm{S}$ and/or $\mathrm{Au}-\mathrm{Cl} \mathrm{CN}$ of 2.6) was observed after $30 \mathrm{~min}$, indicating oxidation of some of the $\mathrm{Au}$-species to $\mathrm{Au}^{3+}$ (Fig. 3A). This increase in $\mathrm{CN}$ above the initial value of 2.0 shows that $\mathrm{Cl}$ is coordinated to the Au-thiosulphate complex. Importantly, the increase in white-line intensity was far less than that with the Au/C-AR catalyst, which is consistent with the lack of induction period for the $\mathrm{Au} / \mathrm{C}-\mathrm{S}_{2} \mathrm{O}_{3}$ catalysts. As with $\mathrm{Au} / \mathrm{C}-\mathrm{AR}$ materials, both EXAFS and STEM- 
HAADF imaging studies (Figures S7d and S13) (22) of the Au/C-S $\mathrm{S}_{2} \mathrm{O}_{3}$ catalysts showed that the Au was almost entirely in an atomically dispersed form (with only a few dimeric species) on the $\mathrm{C}$ support both before and after the in situ experiments. We note that the relative whiteline intensity of the $\mathrm{Au} / \mathrm{C}-\mathrm{S}_{2} \mathrm{O}_{3}$ catalyst at steady state was the same as for the $\mathrm{Au} / \mathrm{C}-\mathrm{AR}$ catalyst at similar activity.

Figure 3C shows that a correlation can be made between the white-line intensity and VCM production of the three active catalysts $\left(\mathrm{Au} / \mathrm{C}-\mathrm{AR}, \mathrm{Au} / \mathrm{C}-\mathrm{HNO}_{3}\right.$ and $\left.\mathrm{Au} / \mathrm{C}-\mathrm{S}_{2} \mathrm{O}_{3}\right)$ throughout their induction periods and at steady state. Across all three catalyst sample sets, which we have shown to be cationic in nature, the VCM productivity can be correlated with white-line adsorptions suggesting the highly dispersed $\mathrm{Au}(\mathrm{I})$ species are crucially important for this reaction and that similar oxidation state species are responsible for the activity in these catalyst systems. However, in all catalysts that are highly active, there is also a population of highly dispersed $\mathrm{Au}(\mathrm{III})$ like species present which could suggest, as originally predicted using correlations with standard electrode potential (3), that the activity is related to a $\mathrm{Au}(\mathrm{I})-\mathrm{Au}(\mathrm{III})$ redox couple. Mechanistically, the reaction could be hypothesised to proceed through the oxidative addition of $\mathrm{HCl}$ to $\mathrm{Au}$ chloride, followed by the addition of acetylene and reductive elimination of VCM through a $\mathrm{Au}(\mathrm{I})$ - Au(III) redox couple. This mechanism has generally been disregarded, as it requires $\mathrm{Au}^{+}$as opposed to the more frequently observed $\mathrm{Au}(\mathrm{III})(32)$. However, under steady state conditions, the $\mathrm{Au}(\mathrm{I}) / \mathrm{Au}(\mathrm{III})$ ratio is $\sim 1.5$, and that activity can be correlated to the presence of $\mathrm{Au}(\mathrm{I})$, as observed in several homogeneous systems $(33,34)$.To investigate the role of $\mathrm{Au}(\mathrm{I})$ further, we have also undertaken a Density Functional Theory (DFT) study of the interaction of $\mathrm{HCl}$ with supported Au species (Fig. 4). Here we focus on $\mathrm{Au}(\mathrm{I})$, by investigating $\mathrm{AuCl}$ on a graphite surface cut in the (119) index plane and hydroxylated on the step edge to stabilise the edge, which is described in detail in the supplementary information. $\mathrm{HCl}$ is added across the $\mathrm{AuCl}$ to form $\mathrm{AuCl}_{2} \mathrm{H}$ with a barrier of 98 $\mathrm{kJ} \mathrm{mol}^{-1}$. This species shows a higher Hirshfeld charge of $0.37 \mathrm{e}$ compared to $0.19 \mathrm{e}$ for the $\mathrm{AuCl}$. The former value is similar to $\mathrm{Au}(\mathrm{III})$ which has a charge of $0.41 \mathrm{e}$, when modelled as $\mathrm{AuCl}_{3}$, indicating that this species has more $\mathrm{Au}(\mathrm{III})$ character. The most stable configuration for a $\mathrm{HCl}$ molecule interacting with $\mathrm{AuCl}$ has a binding energy of $-131 \mathrm{~kJ} \mathrm{~mol}^{-1}$, which compares with $-73 \mathrm{~kJ} \mathrm{~mol}^{-1}$ for $\mathrm{AuCl}_{2} \mathrm{H}$. Dissociation of the $\mathrm{HCl}$ is inhibited by hydrogenbonding interactions; moreover, this site can be easily blocked by additional $\mathrm{HCl}$ and other paths for dissociation are less favorable as $\mathrm{HCl}$ has a lower adsorption energy of $-52 \mathrm{~kJ} \mathrm{~mol}^{-1}$. The generation of VCM can occur via $\mathrm{AuCl}_{2}\left(\mathrm{C}_{2} \mathrm{H}_{3}\right)$, which has an increased stability compared 
to $\mathrm{AuCl}_{2} \mathrm{H}\left(\mathrm{C}_{2} \mathrm{H}_{2}\right)$ with a binding energy of $-224 \mathrm{~kJ} \mathrm{~mol}^{-1}$ compared to $-128 \mathrm{~kJ} \mathrm{~mol}^{-1}$. $\mathrm{VCM}$ is further stabilized with a binding energy of $-269 \mathrm{~kJ} \mathrm{~mol}^{-1}$ but this can be displaced by $\mathrm{HCl}$. The theoretical mechanism, combined with the observation that under in situ conditions the active site is a support gold cation, with a catalytic cycle involving $\mathrm{Au}(\mathrm{I})$ and $\mathrm{Au}(\mathrm{III})$, confirms the original prediction concerning gold being the best catalyst for this reaction based on its standard electrode potential (3). 
Fig. 1. Characterization of a freshly prepared 1 wt $\%$ Au /C-AR catalyst. (A) Representative HAADF-STEM image showing isolated Au species. (B) Powder X-ray diffraction data of this catalyst. (C) Fourier transform of $k^{3}$ weighted $\chi$ EXAFS ex-situ data of the sample and a gold foil reference. Variation in magnitude of Fourier transform is plotted with distance $R$ from the Au absorber. (D) Ex-situ Au L L $_{3}$-edge normalised XANES spectra of the sample and a gold foil reference material.

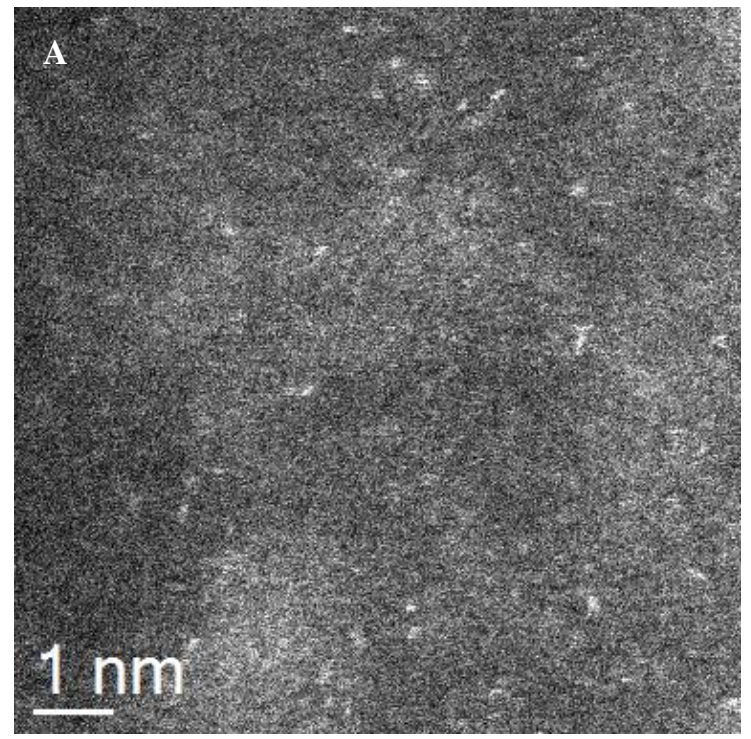

B

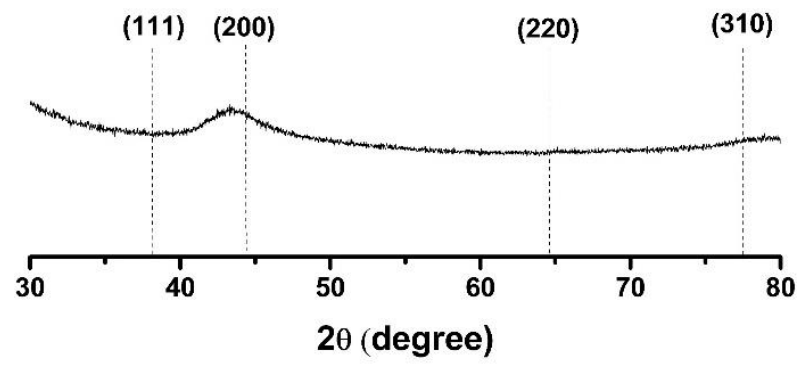

C
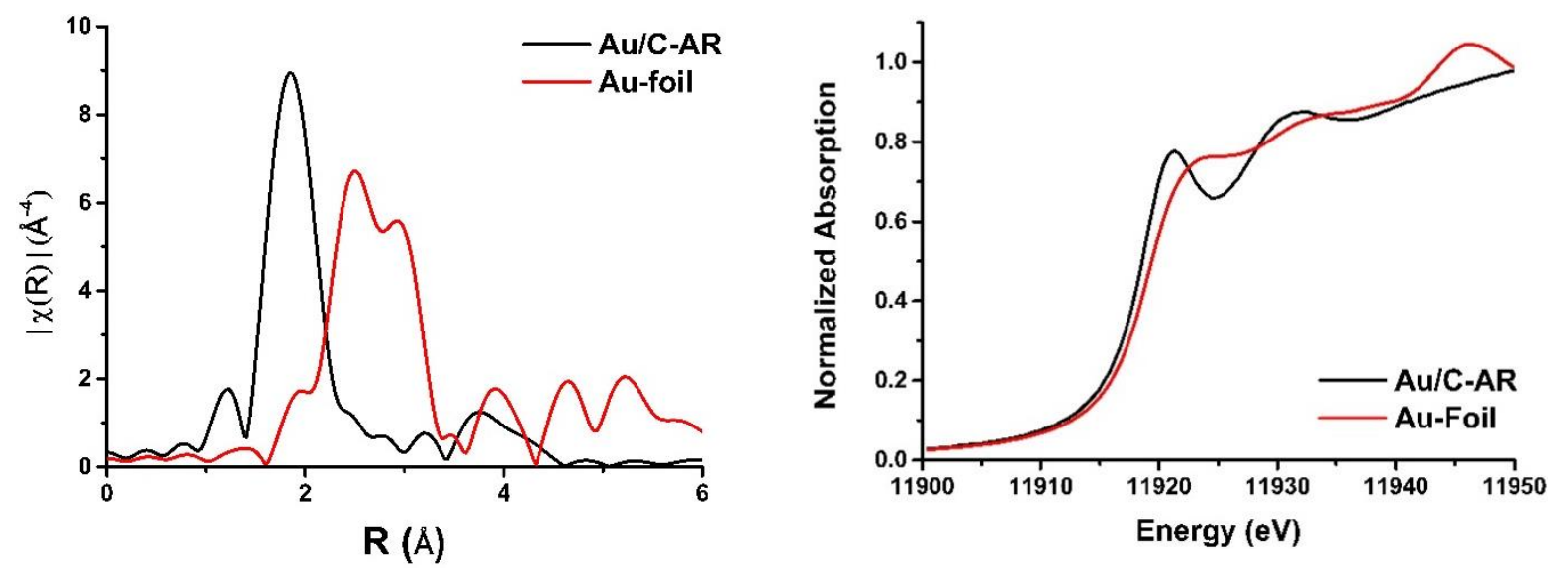
Fig. 2. VCM productivity and in situ characterization of 1 wt $\%$ Au/C-AR catalyst as a function of time-on-line. (A) Catalytic performance as a function of time-on-line (black) and the change in normalised white line intensity (blue) as function of reaction time. (B) 3D profile plot of successive $\mathrm{Au} \mathrm{L}_{3}$-edges from XANES spectra acquired in situ as a function of reaction time. (C) Representative HAADF-STEM image of Au/C-AR after use for 240 min showing the presence of atomically dispersed species and a few occasional sub-nm clusters.
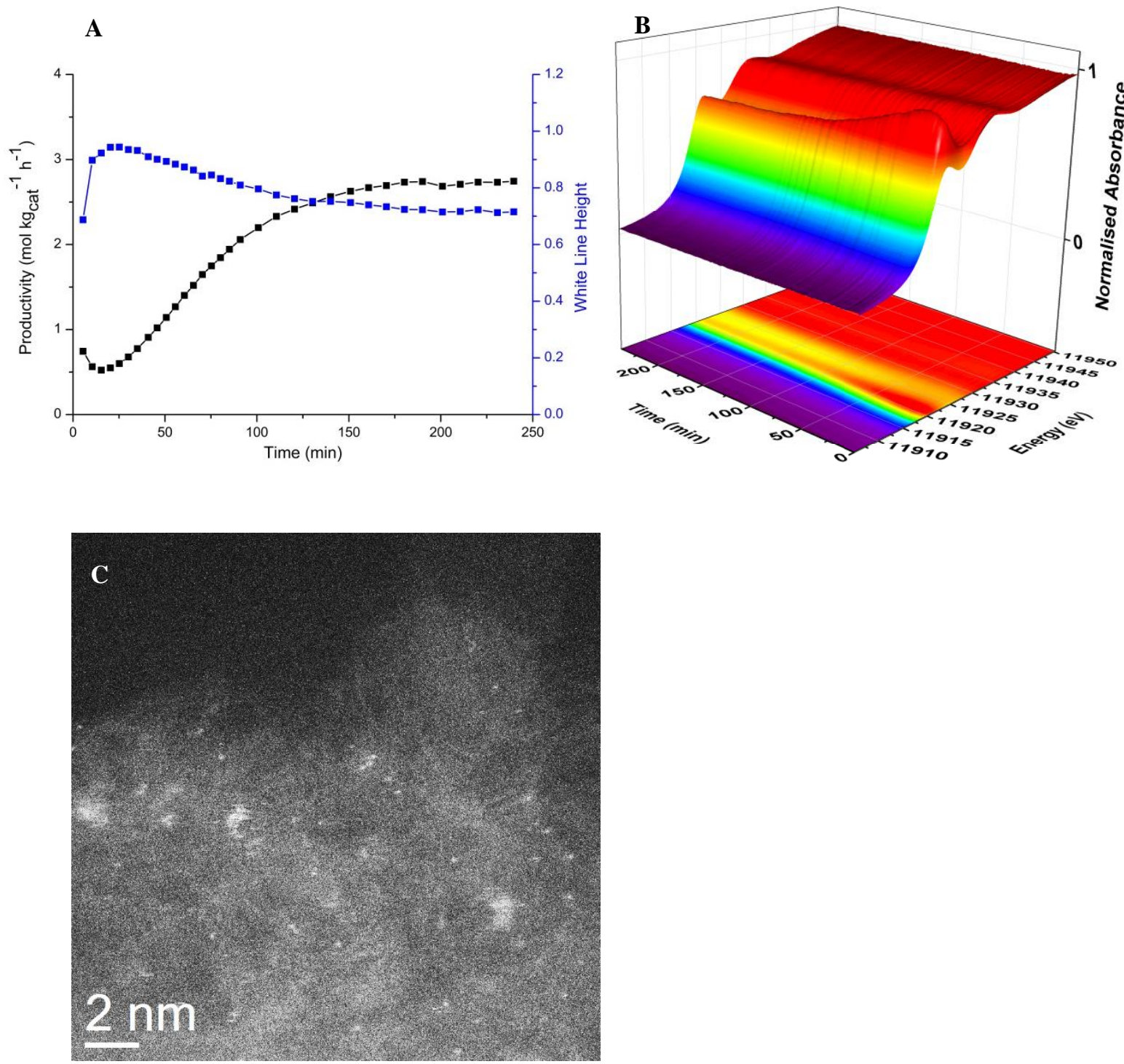
Fig. 3. VCM productivity and in situ XAFS characterization of alternatively prepared 1 wt \% Au/C catalysts ( A)Catalytic activity (black line) as a function of time-on-line for the catalysts prepared with nitric acid, thiosulphate, and with water; the blue lines show the corresponding change in relative white line intensity as function of reaction time. $(\mathbf{B}) \mathrm{k}^{3}$ weighted EXAFS Fourier Transform data for (black) $1 \mathrm{wt} \% \mathrm{Au} / \mathrm{C}-\mathrm{HNO}_{3}$, (blue) $1 \mathrm{wt} \% \mathrm{Au} / \mathrm{C}-$ $\mathrm{S}_{2} \mathrm{O}_{3}$ and (green) $1 \mathrm{wt} \% \mathrm{Au} / \mathrm{C}-\mathrm{H}_{2} \mathrm{O}$ and reference gold foil (red). (C) Dashed lines represent the white line intensities of the $\mathrm{Au}(\mathrm{I})\left[\mathrm{AuCl}_{2}\right]^{-}$standard (value of 0.6) and the $\mathrm{Au}(\mathrm{III}) \mathrm{KAuCl}_{4}$ standard (value of 1.1). [ $\left.\mathrm{AuCl}_{2}\right]^{-}$standard from difference spectra calculated in (18).

A

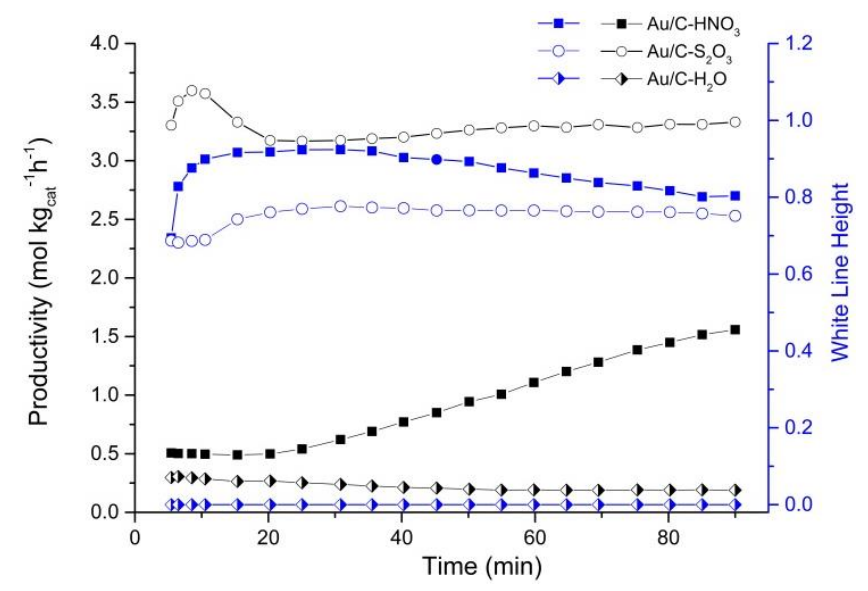

B

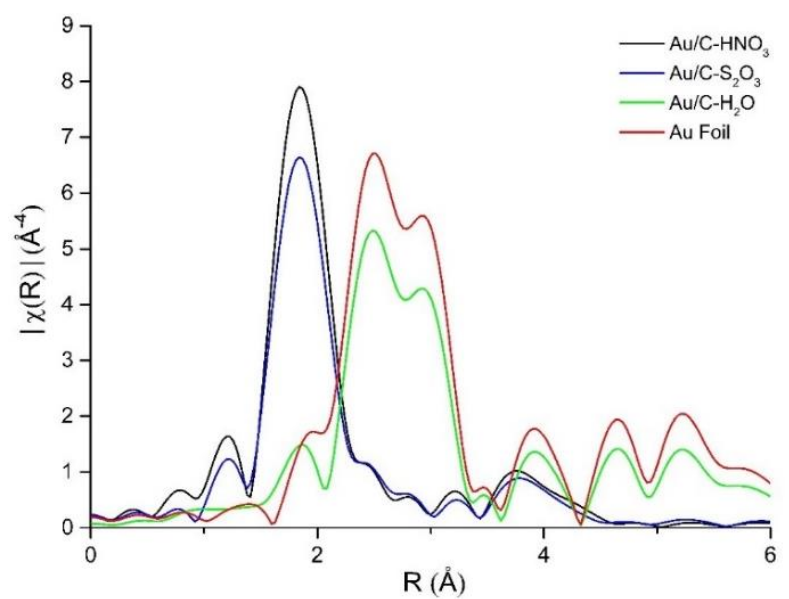

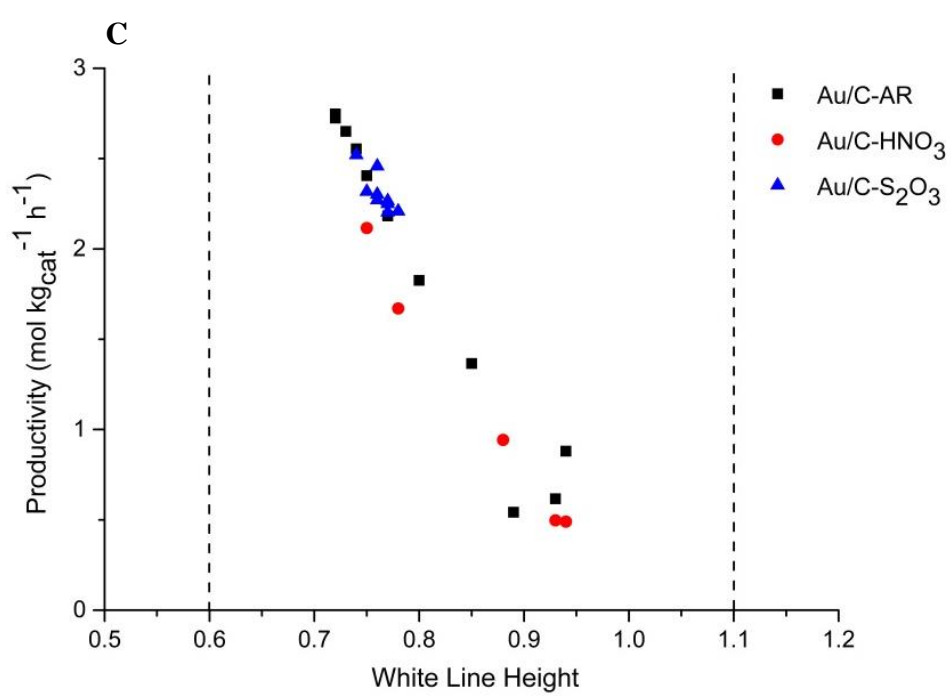


Fig. 4. Mechanism for the transformation of $\mathrm{AuCl}$ to $\mathrm{AuCl}_{2} \mathrm{H}$ and formation of $\mathrm{VCM}$ reproducing AuCl. Key:- Au atoms (gold), $\mathrm{Cl}$ atoms (green), $\mathrm{H}$ atoms (white), C atoms (grey) and $\mathrm{O}$ atoms (red). Energies are given with reference to the geometry optimized configuration of $\mathrm{AuCl}$ on the carbon support and gas phase acetylene and $\mathrm{HCl}$. The inset table shows binding energies for each energy minima and the Hirshfeld charge on each Au atom.
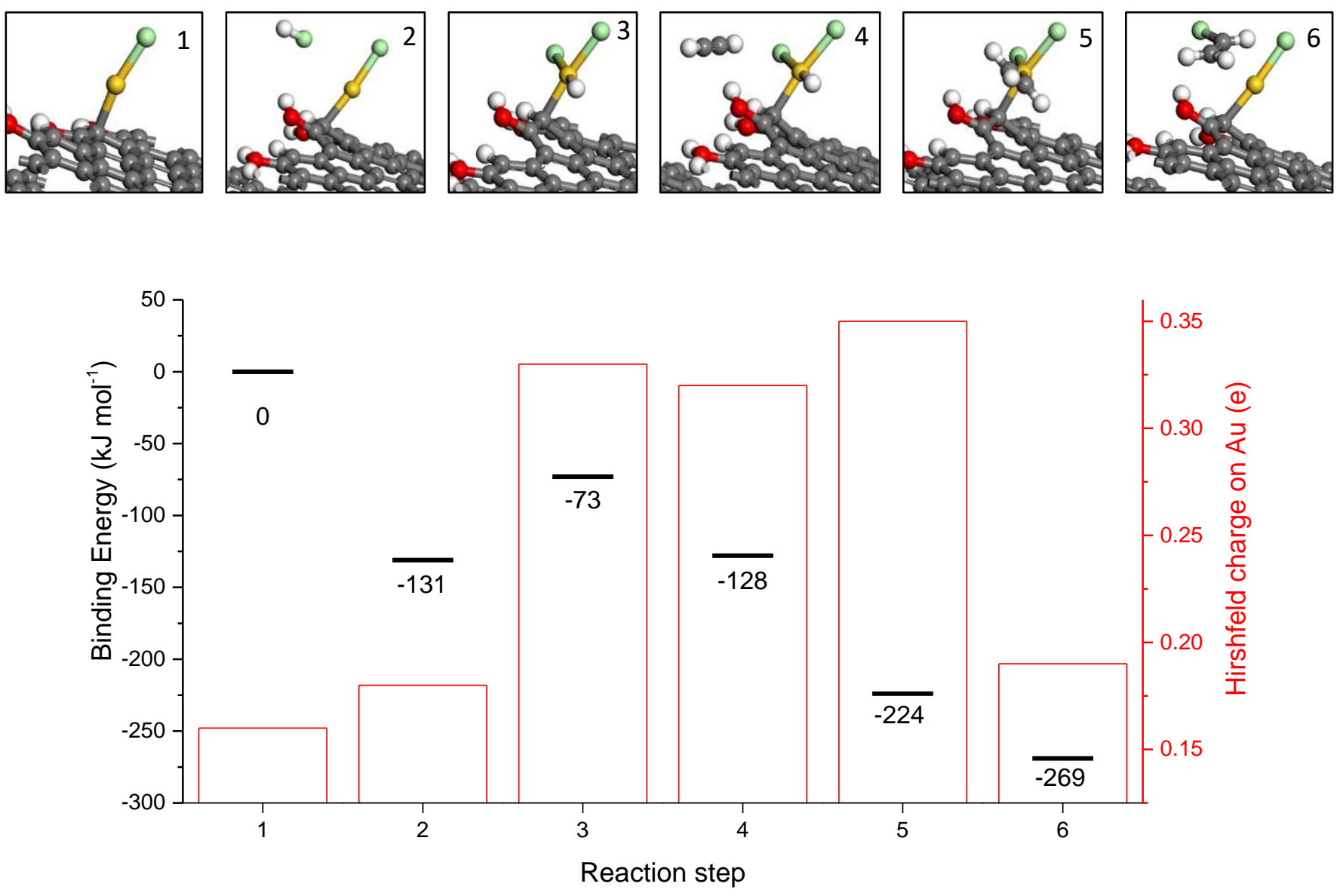



\section{References}

1. P. Johnston, N. Carthey, G. J. Hutchings, J. Am. Chem. Soc. 137, 14548-14557 (2015).

2. R. Ciriminna, E. Falletta, C. Della Pina, J. H. Teles, M. Pagliaro,. Angew. Chem. Int. Ed. 55,14210-14217 (2016)

3. G. J. Hutchings, J. Catal. 96, 292-295 (1985).

4. $\quad$ B. Nkosi, N. J. Coville, G. J. Hutchings, Appl. Catal. 43, 33-39 (1988).

5. $\quad$ http://www.mercuryconvention.org/.

6. $\quad$ B. Nkosi et al., J. Catal. 128, 366-377 (1991).

7. G. Hong et al., RSC Adv. 6, 3806-3814 (2016).

8. M. Zhu et al., ACS Catal. 5, 5306-5316 (2015).

9. X. Tian et al., RSC Adv. 5, 46366-46371 (2015).

10. B. Nkosi, M. D. Adams, N. J. Coville, G. J. Hutchings, J. Catal. 128, 378-386 (1991).

11. X. Liu et al., Catal. Sci. Tech. 6, 5144-5153 (2016).

12. S. Carrettin et al., Adv. Synth. Catal. 348, 1283-1288 (2006)

13. L. Huang et al., Angwe. Chem, Int, Ed. 55, 4808-4813 (2016)

14. A. S. K. Hashmi, Gold Bulletin. 36, 3-9 (2003).

15. M. Flytzani-Stephanopoulos, Acc. Chem. Res.47, 783-792 (2014).

16. W. Deng, A. I. Frenkel, R. Si, M. Flytzani-Stephanopoulos, J. Phys. Chem. C 112, 12834-12840 (2008).

17. J. C. Fierro-Gonzalez, B. C. Gates, J. Phys. Chem. B. 108, 16999-17002 (2004).

18. J. Lu, C. Aydin, N. D. Browning, B. C. Gates, Angew. Chem., Int. Ed. 51, 5842-5846 (2012).

19. M. C. Blanco Jaimes, C. R. N. Böhling, J. M. Serrano-Becerra, A. S. K. Hashmi, Angew. Chem., Int. Ed. 52, 7963-7966 (2013).

20. M. C. Blanco Jaimes et al., Chem. Commun. 50, 4937-4940 (2014).

21. A. S. K. Hashmi et al., Chem. - Eur. J. 16, 8012-8019 (2010).

22. Supporting information is avaliable online (Experimental details, Tables S1-2, Figures S1 - 13, and references 32-44)

23. S.-Y. Chang et al., RSC Adv. 5, 6912-6918 (2015).

24. A. Pantelouris, G. Kueper, J. Hormes, C. Feldmann, M. Jansen, J. Am. Chem. Soc. 117, 11749-11753 (1995).

25. I. Berrodier et al., Geochim. Cosmochim. Acta 68, 3019-3042 (2004).

26. O. Glemser, H. Sauer, Handbook of Preparative Inorganic Chemistry. Academic Press 2, 1056 (1965).

27. P. Hu, P. N. Duchesne, Y. Song, P. Zhang, S. Chen, Langmuir 31, 522-528 (2015).

28. N. Weiher et al., J. Am. Chem. Soc. 129, 2240-2241 (2007).

29. M. Fernandez-Garcia, Catal. Rev. - Sci. Eng. 44, 59-121 (2002).

30. P. T. Bishop, N. A. Carthey, P. Johnston, WO 2013/008004A3, May 16, 2013.

31. R. A. Bryce, J. M. Charnock, R. A. D. Pattrick, A. R. Lennie, J. Phys. Chem. A. 107, 2516-2523 (2003).

32. M. Conte et al., J. Catal. 250, 231-239 (2007).

33. M. Pernpointner, A.S.K. Hashmi, J. Chem. Theory Comput. 5, 2717-2725 (2009).

34. A.S.K. Hashmi, Angew. Chem. Int. Ed. 51, 12935 - 12936 (2012).

35. A. Pantelouris, G. Kiiper, J Homes, C. Feldmann, M. Jansen, J. Am. Chem. Soc., 117, 11749-11753 (1995). 
36. D. Tibiletti, A. Amieiro-Fonseca, R. Burch, Y. Chen, J. M. Fisher, A. Goguet, C. Hardacre, P. Hu, D. Thompsett, J. Phys. Chem. B, 109, 22553-22559 (2005)

37. G.J. Sherborne, B.N. Nguyen, Chemistry Central Journal , 9, 37 (2015)

38. B. Ravel, M. Newville, J. Synchrotron Radiat., 12, 537-541 (2005)

39. M. Newville, J. Synchrotron Radiat., 8, 322-324 (2001).

40 S. J. Clark, M. D. Segall, C. J. Pickard, P. J. Hasnip, M. J. Probert, K. Refson, M.C. Payne. Zeitschrift fuer Kristallographie, 220, 567 (2005).

41. N. Govind, M. Petersen, G. Fitzgerald, D. King-Smith, J. Andzelm, Comput. Mater. Sci., 28, 250 (2003).

42. $\quad$ E.R. McNellis, J. Meyer, K. Reuter, Phys. Rev. B, 80, 205414 (2009).

43. A. Tkatchenko, M. Scheffler, Phys. Rev. Lett., 102, 073005 (2009).

44. A.P. Seitsonen, A.M. Saitta, T. Wassmann, M. Lazzeri, F. Mauri, Phys. Rev. B, 82, 115425 (2010).

45. R. Burgess, C. Buono, P.R. Davis, R.J. Davis, T. Legge, A. Lai, R. Lewis, D.J. Morgan, N. Robinson, D.J. Willock, J. Catal., 323, 10 (2015).

46. H. Kitagawa, N. Kojima, T. Nakajima, J. Chem. Soc. Dalton Trans., 3115 (1991)

47. H. Kitagawa, N. Kojima, T. Nakajima, J. Chem. Soc. Dalton Trans., 3121 (1991)

\section{Acknowledgments}

We acknowledge Cardiff University for support as part of the MAXNET Energy consortium. We would also like to thank Prof. R. Schlögl for helpful discussions. UK Catalysis Hub is kindly thanked for resources and support provided via our membership of the UK Catalysis Hub Consortium and funded by EPSC (grants EP/K014706/1, EP/K014668/1, EP/K014854/1EP/K014714/1and EP/M013219/1).

We used the B18 beamline at the Diamond Light Source (allocation numbers SP11398 and SP15214) with the help of D. Gianolio and G. Cibin. CJK gratefully acknowledges funding from the National Science Foundation Major Research Instrumentation program (GR\# MRI/DMR-1040229). We thank Johnson Matthey for their contribution to and funding of this work. Calculations were performed via our membership of the UK's HEC Materials Chemistry Consortium, which is funded by EPSRC (EP/L000202), this work used the ARCHER UK National Supercomputing Service (http://www.archer.ac.uk). In addition, local HPC services at UCL were used on the Grace computer. We thank S. Morris, A. Davies and L. Wescombe for technical support. All the data contained in this paper are archived at DOI: 10.17035/d.2017.0032403846. 


\section{Supplementary materials}

Materials and Methods

Figs. SE1 and SE2

Figs. S1 to S13

Tables S1 and S2

References (35-47) 